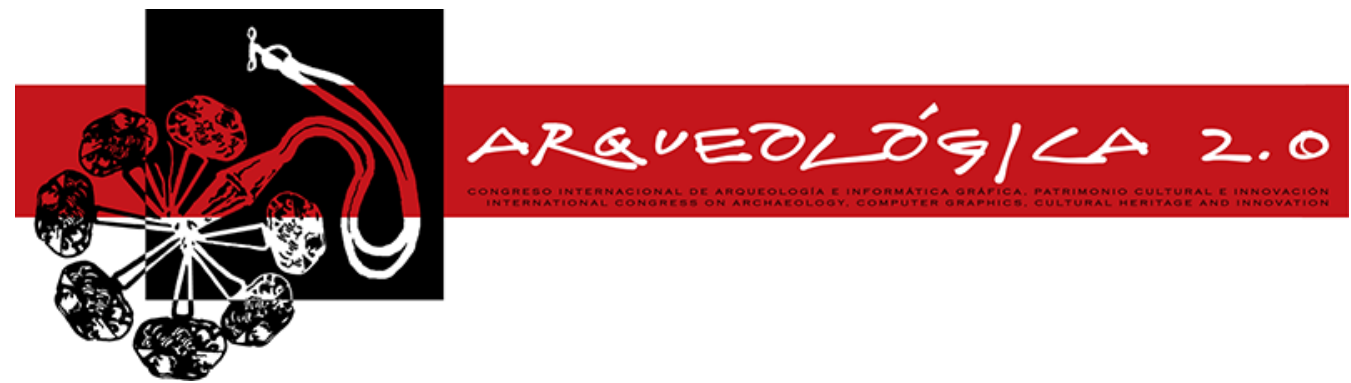

Proceedings of the $8^{\text {th }}$ International Congress

on Archaeology,

Computer Graphics,

Cultural Heritage and Innovation

'ARQUEOLÓGICA 2.0'

in Valencia (Spain),

Sept. 5-7, 2016

DOI: http://dx.doi.org/10.4995/arqueologica8.2016.3554

Received: 01/03/2016

Accepted: 25/06/2016

\title{
DEVELOPMENT OF AN EFFICIENT APPROACH OF ARCHAEOLOGICAL HERITAGE IN THE INTERTIDAL ZONE OF THE BELGIAN NORTH SEA
}

\author{
Michiel Decock ${ }^{a}{ }^{,}$, Cornelis Stal ${ }^{a, b}$, Samuel Van Ackere ${ }^{a}$, Annelies Vandenbulcke ${ }^{a}$, Philippe De \\ Maeyer ${ }^{\mathrm{a}}$, Alain De Wulf ${ }^{\mathrm{a}}$

\begin{abstract}
a Department of Geography, Ghent University, Krijgslaan 281 (building S8), Ghent, Belgium. Michiel.Decock@Ugent.be; Alain.Dewulf@Ugent.be
\end{abstract} \\ Cornelis.Stal@Ugent.be; Samuel.Vanackere@Ugent.be; Annelies.Vandenbulcke@Ugent.be; Philippe.Demaeyer@Ugent.be; \\ ${ }^{\mathrm{b}}$ Department of Real Estate and Land Surveying, University College Ghent, Valentin Vaerwyckweg 1 (building P), Ghent, Belgium.
} Cornelis.Stal@HoGent.be

\begin{abstract}
The knowledge of the submerged cultural heritage in the North Sea is rather limited. The Belgian North Sea is being used for a lot of different purposes, such as fishing, aggregate extraction, wind farms, dredging, etc. Due to these increasing economic activities, the underwater archive is in danger. In the context of the UNESCO Convention on the Protection of the Underwater Cultural Heritage of 2001, gathering more information about the submerged cultural heritage in the intertidal zones of the North Sea is one of the main objectives of the Belgian scientific project 'SeArch'. It will give a clearer picture of the broader cultural and archaeological heritage in the region and it can be used as a basis for a sustainable management by government agencies. The Department of Geography (Ghent University, Belgium) contributes to the SeArch project in two ways. First, an innovative survey methodology has been developed which allows an accurate and cost-efficient evaluation of the archaeological potential in the intertidal zones of the Belgian beaches. Secondly, the Department of Geography is developing an interactive webGIS platform, which makes it possible to share, integrate and visualize the gathered archaeological and environmental data and information in a user-friendly way. Hereby, the total potential of this project is fully exploited in a time-efficient manner. To create an interactive webGIS platform, a good structured spatial database is needed. It enables manipulation of a wide variety of georeferenced information in both raster and vector formats. This paper provides more information about the configuration and application of the spatial database. Moreover, it focusses on the development of a fully functional Spatial Data Infrastructure (SDI) using the most reliable, powerful and state-of-the-art technological components. Besides, a new way of collecting geomatic data in a fast and accurate manner will be discussed. Some processing results will show the possibilities for detecting and visualizing underground structures and archaeological objects.
\end{abstract}

Key words: North Sea, submerged cultural heritage, 3D data acquisition, Spatial Data Infrastructure, Geo Web-Service

\section{Introduction}

During the last glacial period (approx. 110,000 to 12,000 years ago, also called the Weichselien), a vast amount of water crystallized. This resulted in much lower sea levels. At those times, the level of the North Sea was even $130 \mathrm{~m}$ below the current one. As a result, many regions in the current North Sea were suitable for terrestrial organisms to live, such as mammoths, sabertoothed cats and pre-historic men. When the temperatures on Earth started to rise, the ice poles melted, causing the flooding of those regions. This is the reason why so many archaeologic artefacts and structures are found in the bottom layers of the North Sea. Because the water bulk acts as a protection layer against natural degradation processes, the finds are mostly well preserved.

The knowledge of the underwater cultural heritage in the Belgian part of the North Sea (Fig. 1) is rather limited. Nevertheless, this submerged heritage forms an important aspect of our cultural heritage and offers huge possibilities for scientific and (inter-)cultural purposes. Due to an increasing number of economic activities at sea (aggregate extractions, fishing, dredging, wind farms, etc.), this unique underwater archive is in danger. But this is not the only threat. Due to the very complex state structure of Belgium, a solid regulation regarding underwater cultural heritage is still lacking, notwithstanding the awareness of the need to take responsibility for this heritage in danger at the political level. According to the UNESCO (2001) Convention on

`Corresponding Author: Michiel Decock, Michiel.Decock@Ugent.be 
the Protection of the Underwater Cultural Heritage, the mapping and preservation of archaeological finds is even mandatory, as well as promoting the public awareness and the exchange of information. The multidisciplinary 'SeArch' project (Archaeological Heritage in the North Sea, www.sea-arch.be) offers solutions to these challenges through the development of an efficient assessment methodology and an approach towards a sustainable management policy and legal framework. Apart from the Department of Geography of Ghent University (www.geoweb.ugent.be), there are several other collaborating partners, each specialized in their own discipline (archaeologists, lawyers, geologists, marine specialists): Flanders Marine Institute (VLIZ, www.vliz.be), Flemish Heritage Agency (FHA, www.onroerenderfgoed.be), Deltares (Department of Geology and Geophysics, The Netherlands, www.deltares.nl), Renard Centre of Marine Geology (Ghent University Department of Geology, www.rcmg.ugent.be ) and the Maritime Institute (Ghent University Department of European, Public and International Law, www.ugent.be/re/epir/en/research groups/public-international-law/department/maritime institute/maritimeinstitute.htm).

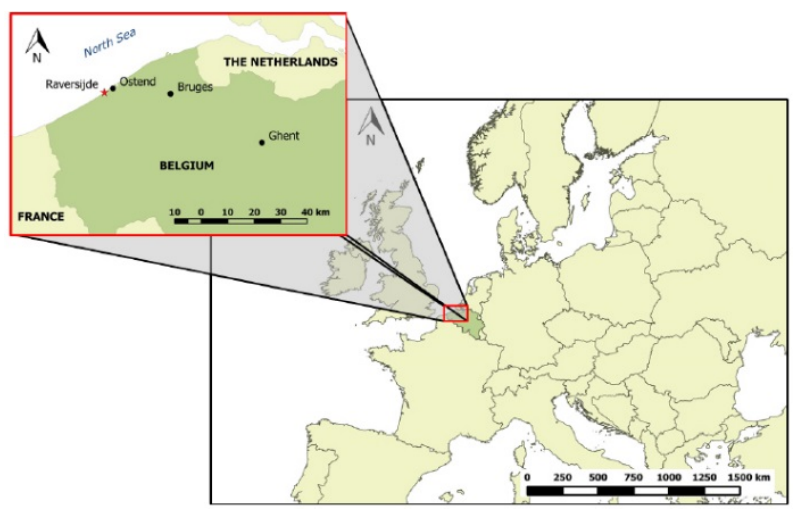

Figure 1: Geographic location of Belgium in Europe with detail map focused on the survey region of Raversijde

The contribution of the Department of Geography, Ghent University, comprises two aspects. First, there was an urgent need for an innovative survey methodology which allows an accurate and cost-efficient evaluation of the archaeological potential in the intertidal zones of the Belgian coast line. Conventional topographic and bathymetric surface modelling methodologies are not sufficient for these areas and new surveying approaches are required. This paper describes a new way for collecting geomatic data on beaches. This will be followed by some data processing, showing the great possibilities for detecting and visualizing underground structures and archaeological objects.

Secondly, the archaeological and environmental data resulting from the surveys within this project, as well as already existing data, have to be investigated using a Spatial Data Infrastructure (SDI). The objective of this SDI is to increase the accessibility and interoperability of spatial data for a wide range of users. A web-based Geographical Information System/Service (webGIS), as part of the SDI, will allow an efficient integration and visualization of the data in a user-friendly way in accordance with clearly defined protocols. The interface is useful for dissemination of information and for support of decision makers. One of the major challenges for spatial data users is the integration of multi-source spatial data. Within the framework of this project, datasets come from different actors, which are operated by different institutions. Consequently, there are many heterogeneities and inconsistencies in the technical and non-technical aspects of the different (spatial) datasets. In spite of the heterogeneity of the datasets, the use of a SDI facilitates the data integration and interoperability. The SDI provides a holistic platform for users to interact with spatial data through technical and non-technical tools (Mohammadi et al. 2008). This paper will explain the advantages of storing archaeological data purely based on their specific characteristics. In this way, different objects with similar characteristics can be linked to one another and adjustments of existing data can be easily done.

\section{Methodology}

\subsection{Data acquisition}

At first sight, Airborne Laser Scanning (ALS) seemed to be the most appropriate data acquisition technique for measuring the intertidal zone. However, there are some reasons why this is not the case. The most obvious one is that airborne methods are very expensive for measuring only a relatively small region. More important though is the fact that airborne methods are not accurate enough for the scope of this project. Objects not too deep below the surface have an influence on the microrelief of sandy beach structures. In this way, knowledge of possible micro-ripples on a temporal base offers the possibility to detect archaeological findings; if certain micro-ripples at a specific place are existent at different times, this indicates an object might be beneath the surface. As the local stockpiling of sand grains is of the order of a few millimetres, there is a need to distinguish sub-centimetre height variations. Airborne methods only have an accuracy of about one decimetre (Middleton et al. 2013).

Solely relying on ALS for detecting small sub-soil finds in the intertidal zone is not sufficient. This has been confirmed based on ALS measurements of the Flemish Hydrography (http://www.vlaamsehydrografie.be), which scans the Belgian coast twice a year and after each storm. Based on those data, no small archaeological objects have yet been found. However, ALS can be used to detect interesting archaeological sites, as was extensively done in e.g. Baden Württemberg (Hesse 2010).

To deliver the necessary vertical accuracy of about 1 $\mathrm{mm}$, a range of terrestrial solutions was considered. A short description of each of these techniques is given below, as well as their respective advantages and limitations.

\subsubsection{Robotic Total Station}

Recent developments towards robotic total stations made it possible to perform reflectorless distance measurements (EDM) by only one operator, significantly increasing the performance of total station measurements. The use of such a total station for surface mapping may result in an accuracy of about 1 to $2 \mathrm{~cm}$, although sub-centimetre single point precisions can be reached. Another interesting development is the 
integration of total stations with imaging sensors. An important drawback is the low point density due to the slower measurement speed (in comparison with laser scanners) and the higher degree of manual intervention by the operator.

\subsubsection{Real-Time Kinematic GNSS}

Until a few years, it was very difficult and expensive to measure single points with $\mathrm{cm}$ accuracy. Moreover, these measurements were extremely time-consuming. The ability to use data connections over mobile networks have sped up the development of Real-Time Kinematic (RTK) GNSS measurements with $\mathrm{cm}$ accuracy. The Flemish Positioning Service (FLEPOS) is the implementation of such a system in Flanders, consisting of a network of 40 permanent reference stations. Users can use this FLEPOS service by downloading real-time correction messages for their own GNSS measurements. By using FLEPOS, point precisions between $2 \mathrm{~cm}$ in planimetry and $4 \mathrm{~cm}(67 \%$ or 1 sigma) in altimetry can be reached. This easy access to very accurate GNSS measurements has opened a lot of possibilities to use GNSS for the fast and accurate generation of Digital Surface Models (DSM). The technique is still limited by the achievable resolution of the measurements. Assuming a mobile vehicle equipped solely with RTK-GNSS but without inertial system and laser scanning, extra error sources are introduced by the sinking of the wheels into the sand surface and the inclination of the GNSS pole.

\subsubsection{Static Terrestrial Laser Scanning}

Static Terrestrial Laser Scanning (STLS) is a technique where a huge amount of accurate detail points is acquired from a fixed laser scanner position. STLS is frequently used to model objects of limited size or at a limited distance from the scanner. The type of application and the range is in this context mainly related to the type of distance measurement (i.e. phase-based with a range up to $100 \mathrm{~m}$ or pulse-based with a range up to $1 \mathrm{~km}$ ). Its main advantage consists of the high scanning rate of up to $1 \mathrm{GHz}$, which leads to an accurate $3 \mathrm{D}$ model which offers a point based representation of the object or site.

The technique can be used for topographic surface modelling, but it is obvious that STLS suffers from some important drawbacks for intertidal zone mapping. The number of scans is related to the size of the area that has to be scanned. Because of the lack of topographic variability of the terrain, a target based registration is required. Since each target, or materialized reference point, has to be positioned in a coordinate system, large campaigns are very time consuming. Another drawback of static measurements is the fact that on flat terrains, the angles of incidence will be very large and the range limited. The scanner is placed on a tripod (Fig. 2), meaning that the scanning height is around 1.50 to 2.00 $\mathrm{m}$. Even with a range of $8.50 \mathrm{~m}$, there will be an incidence angle of 80 degrees, resulting in weak reflection and large beam spots. Thereupon, lower signal to noise ratios will occur and lower point accuracies will be reached. Summarizing, it can be concluded that STLS will be very useful for the detailed modelling of small surfaces, but limited on speed, coverage and accuracy for the mapping of larger areas.

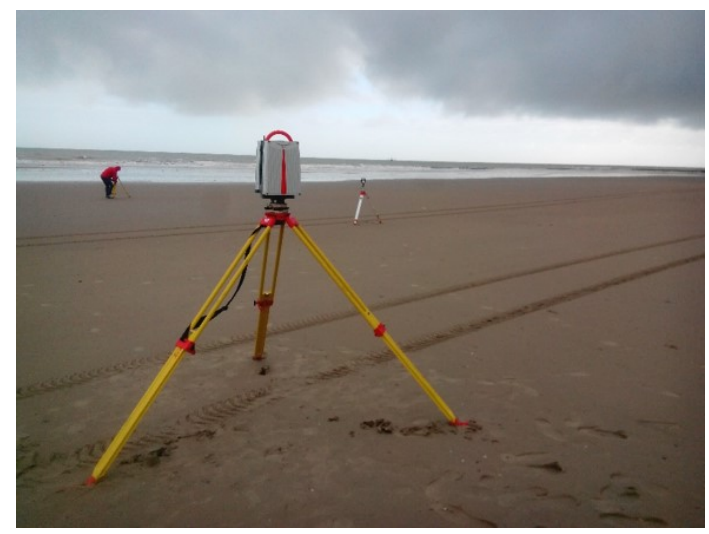

Figure 2: STLS at Raversijde

\subsubsection{Photogrammetry or image based modelling}

Photogrammetry or image based modelling is frequently executed by means of an airborne laser scanner, but next to this classic mapping technique, Kite Aerial Photogrammetry (KAP) is a promising alternative (Fig. 3). KAP can be used to create DSMs in a fast and accurate way for mapping and monitoring sand dunes and particular areas of interest situated directly along the coastline. The resulting models can be used after a storm surge, to assess the need of beach nourishment, to evaluate coastal erosion or when new constructions need to be placed along the coastline.

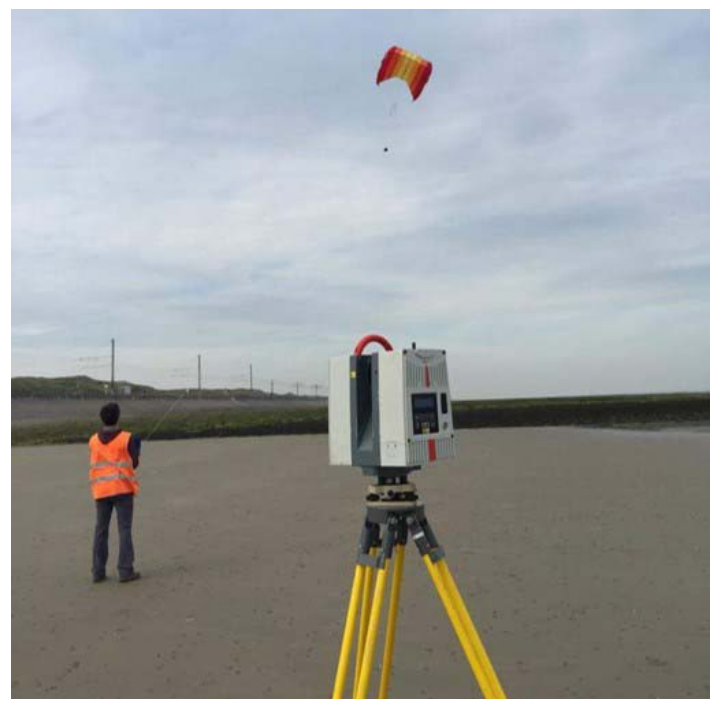

Figure 3: Image based modelling using a kite (KAP)

The principle of KAP is similar to that of conventional airborne campaigns. An important factor consists of the weather conditions. The kite system can be used in conditions from 2 (light breeze) to 6 (fresh breeze) on the Beaufort scale. This in contrast to the use of Unmanned Aerial Vehicles (UAV), which need to operate in less windy conditions (2-3 Beaufort). The procedure involves the kite operator walking around the beach, on which ground control points (GCPs) have been placed as black-and-white targets. To achieve the best positional accuracy, GCPs are surveyed with a total station. The kite has a working altitude of 10 to 20 meters above ground level. The kite carries a shock- and waterproof, non-metric compact camera with a smallsize 12 till 20 Megapixel sensor. This camera makes it 
possible to acquire images with a ground resolution of less than $5 \mathrm{~cm}$. Afterwards, photogrammetric processing is used to combine the photographs into a mosaic. The aerial triangulation with camera calibration and subsequent model generation is mostly an automated process. The photomosaic is georeferenced and orthorectified using the GCPs. In one day, an area of up to 10 ha can be surveyed and processed to produce digital height maps and orthorectified images. Kite systems can be used as an addition to classic topographic surveys and aircraft-based surveys, with considerable gains in the cost of the data acquisition.

\subsubsection{Mobile Terrestrial Laser Scanning}

Considering the drawback of the aforementioned techniques (accuracy, speed, coverage), a Mobile Terrestrial Laser Scanning (MTLS) system was considered to survey the intertidal zones. The system configuration of the used MTLS is very similar to an ALS set-up. The main components consist of a laser scanner, an Inertial Navigation System (INS) and a Global Navigation Satellite System (GNSS), depicted in Figure 4. These instruments were mounted on a moving platform: an 8 wheeled vehicle called ARGO (Fig. 5). As in airborne applications, the combination of GNSS and INS measurements with the Position and Orientation measurement System (POS) provides highly accurate positioning. In turn, the laser scanner produces a very precise point cloud. The accurate determination of the calibration parameters is also essential for the correct use of MTLS (Skaloud and Lichti 2006). This state-ofthe-art survey method was developed by Prof. Dr. Nicolas Seube (Seube et al. 2012) and his research team of ENSTA Bretagne, Brest (École Nationale Supérieure de Techniques Avancées, http://www.enstabretagne.fr), who also cooperated with the field campaigns.

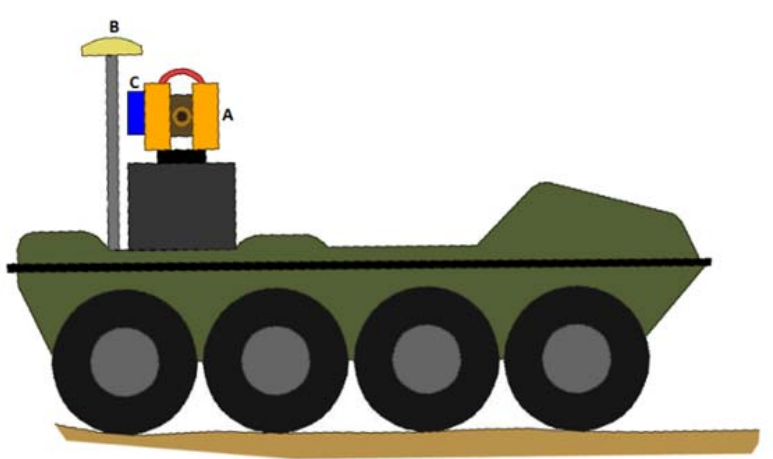

Figure 4: Illustration of the set-up of the survey main components: A) laser scanner, B) GNSS and C) INS

Using laser scanning, the distance between an object and the sensor is derived using a beam of monochromatic light. A large number of distance and angular measurements will result in a very dense point cloud within a limited time frame; for each beach strip (approx. $150 \mathrm{~m}$ by $300 \mathrm{~m}$ ) the scanning time was only about 45 minutes. However, most part of the time is spent on the calibration procedure (about half a day). All types of laser scanning systems use active, optical, reflection based and contact-free scanning methods. Here, the used laser scanning device (Leica HDS6100) determines the distance based on the calculation of the phase difference between the emitted and reflected continuous wave with a maximum scan rate of 508,000 points/s. Hereby, the used electromagnetic radiation has a wavelength of approx. $650 \mathrm{~nm}$.

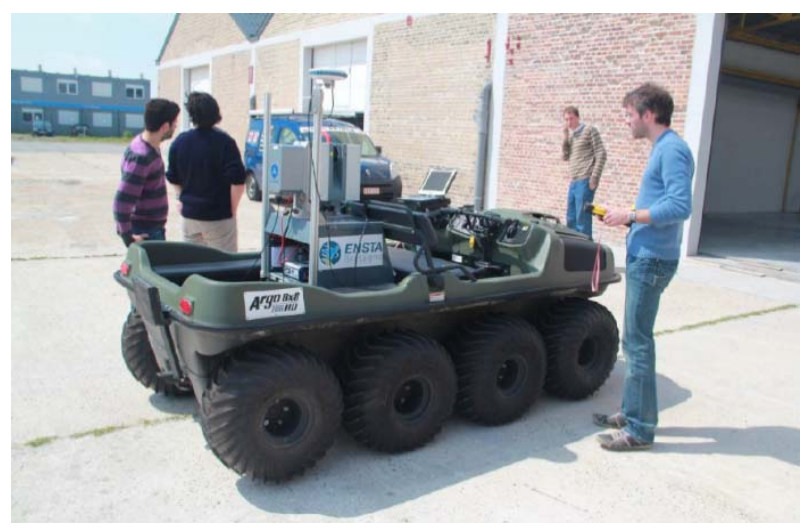

Figure 5: The used amphibious vehicle ARGO with equipment

To verify and analyse the accuracy of the DEMs created using the MTLS technique, a theoretical and practical comparison of the various other described survey methods was made (robotic total station, Real-Time Kinematic (RTK) GNSS, STLS and conventional photogrammetry).

\subsection{WebGIS platform}

Another contribution of the Department of Geography to the SeArch project is the development of a new and specific Spatial Data Infrastructure (SDI) of the archaeological and geologic/geophysical data. Its main purpose is to maximally integrate those data and to visualize them in a user-friendly way. A SDI encompasses organizational or institutional arrangements and policies, as well as the desired technology, which is needed to make geographical data available. SDI components are amongst others: geographic data, metadata, technical specifications and standards, procedures for the coordination of the infrastructure, arrangements for the availability and use of geographic data, etc.

Figure 6 depicts the use of the web-based Geographic Information System (webGIS) for both the deliverance and request of archaeological information. Hereby, solely open-source software is used. By means of QGIS (www.qgis.org), the administrator puts archaeologic and geologic/geophysical data in a spatial database (arrow 1). PostGIS (www.postgis.net) adds extra elements to the object related database, such as geometry, geography and the creation of a raster. With the aid of open standards, data from the database can be published (arrow 2). The end user is able to view those data in a web browser, where they are visualized on a map (arrow 3). This is done by means of an open-source server written in Java, GeoServer (geoserver.org), which generates cartographic products of the data. GeoServer is designed for interoperability, such that any major geospatial data source can be published, based on the open standards set forth by the Open Geospatial Consortium (OGC, www.opengeospatial.org). In turn, OpenLayers (www.openlayers.org) is a public JavaScript library for showing geo-data in a web browser. The usage of pre-rendered maps (tiles) is necessary for a 
fast visualization of the maps. GeoWebCache (www.geowebcache.org) accelerates the output of tiles from GeoServer (arrow 4).

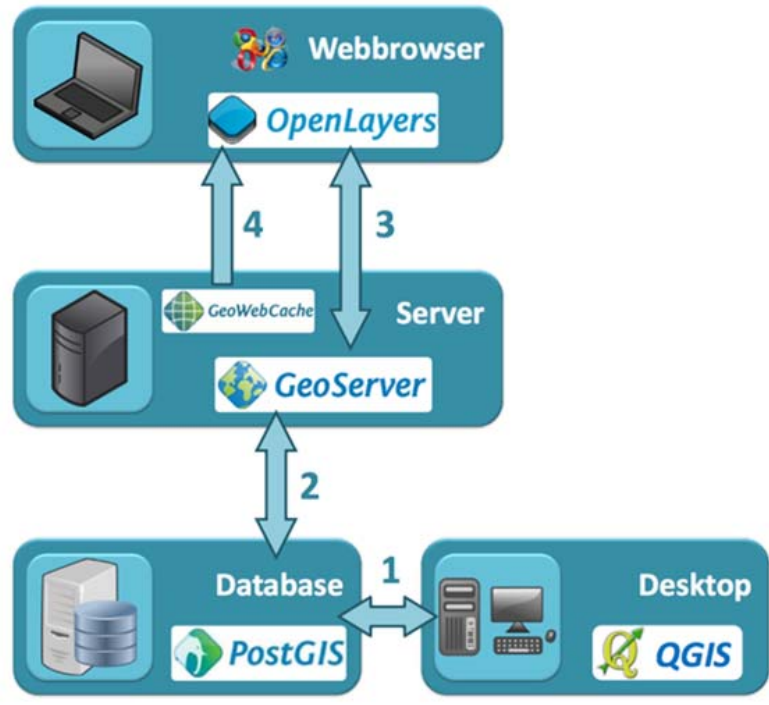

Figure 6: Schematic overview of the webGIS

The SeArch web application is based on a flexible and linkable data structure. It mainly consists of nodes with properties and relations between them. In this way, no rigid structure has to be followed by archaeological organizations for the huge variety of archaeological objects. For example, a Roman amphora has totally different characteristics (material, height, location, preservation condition, etc.) compared to a $20^{\text {th }}$ century warship. Consequently, no tables with large amounts of empty cells or default values exist in the database. Moreover, this data structure is suitable for different application domains of archaeology and cultural heritage, from research to conservation management.

Figure 7 is an example of the used data structure. Nodes form the main concept and correspond to the archaeological object (e.g. 3 blade propeller, plane wreck, bayonet). The nodes can have relations between them. Their type is designated in the data structure by the concept property, for example the location or kind of material. To each property there is a value assigned (e.g. wood for material, $50^{\circ} \mathrm{N} 10^{\circ} \mathrm{E}$ for location) and together they build up the relation vertex.

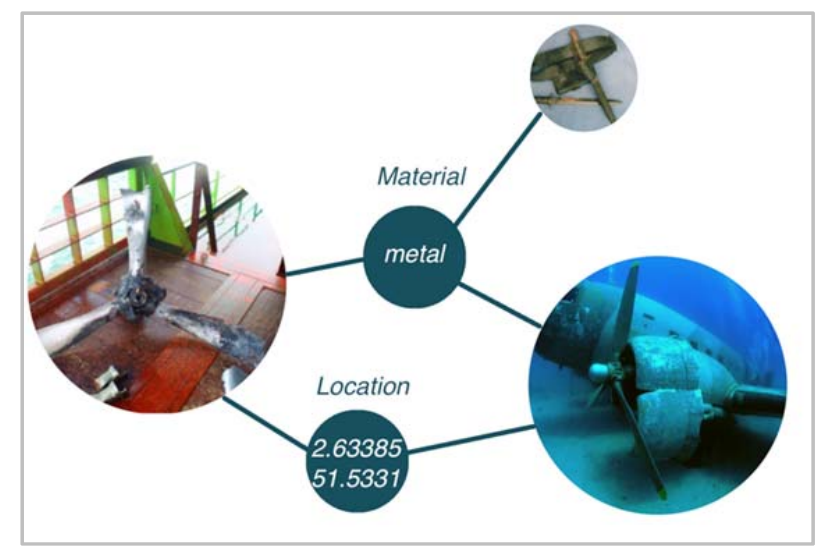

Figure 7: Example of the data structure
Building a web-based application on this data structure enables dissemination of information, collaboration and discussion on the data and their interpretation, quickly acquiring and editing information, etc. Due to the geographical nature of most archaeological data, a geodatabase is used for the storage of the data and information. In this way, an archaeological data infrastructure is set up, which serves as a web-based GIS and can function as a shared virtual workspace. This approach, therefore, agrees with the ideas proposed by Snow et al. (2006) regarding cyber tools for archaeology.

Figure 8 is an example of the kind of maps which can be found on the webGIS platform (www.sea-arch.be). It shows the currently found shipwrecks in the Belgian part of the North Sea, altogether with the present shallow zones. In this way, knowledge of the spots of the shipwrecks and the local height of the sea level can be linked to one another, which are totally different kinds of data. Apart from archaeological object related maps, the website also contains a large number of maps depicting natural structures, such as soil layers of pre-historical eras.

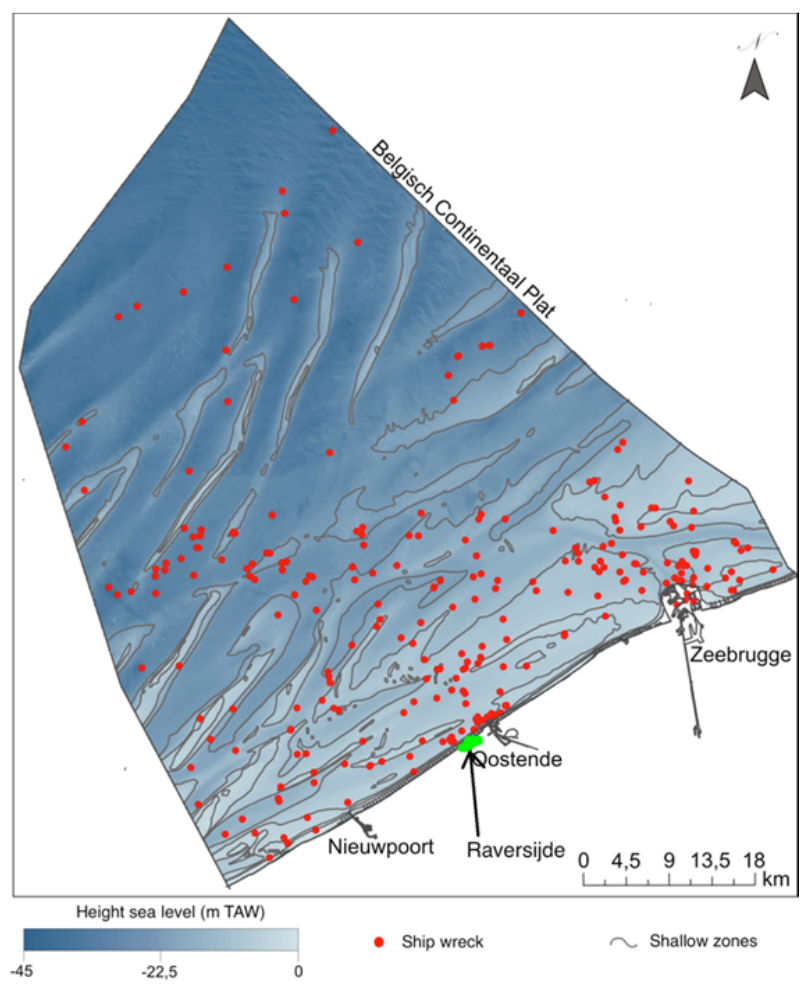

Figure 8: Shallow zones and locations of shipwrecks in the Belgian part of the North Sea

\section{Data acquisition and processing results}

To collect the data on site, several surveys were organized at the beach of Raversijde, Belgium (June 2013, May 2015 and May 2016). As illustrated in Figure 9 , the beach is totally covered with sand and it was selected based on its high archaeological potential (Ervynck et al. 1999). The submerged village of 'Walravenside' is situated in the intertidal zone of the beach and some archaeological features appeared during neap tide a few decades ago. The detection of these finds using micro-topographical enhancement techniques is one of the goals of this project. The 
measured sections are separated by breakwaters and are represented by hashed lines in Figure 10.

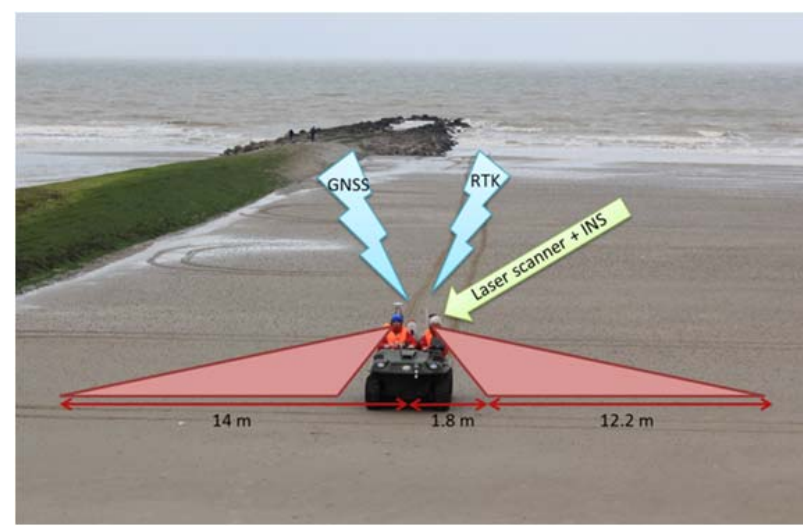

Figure 9: The ARGO at work on the beach of Raversijde, Belgium

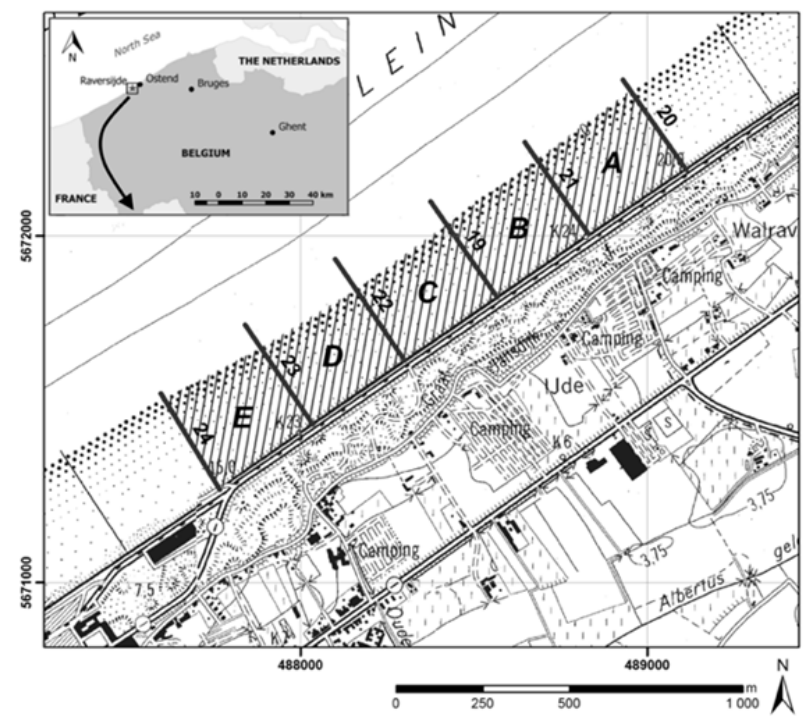

Figure 10: Overview of the study area in Raversijde, Belgium. The five test areas are indexed from $A$ to $E$ (source background map: NGI)

The survey zones $A$ till $E$ in Raversijde can be approximated by a surface with an inclination of $1.7 \%$. The breakwaters are spaced by approx. $300 \mathrm{~m}$. Incoul et al. (2014) have demonstrated that a maximal range of 14 $\mathrm{m}$ can be accepted for topographic surface modelling under these conditions, with a typical scanning height of $1.60 \mathrm{~m}$. Various parallel lines were driven with an overlap between consecutive strips. This overlap allowed a quality assessment, as well as removing the blind spot underneath the vehicle. A series of STLS measurements was also executed on the beach to perform an extra quality assessment on the data, where the STLS point clouds were georeferenced using a target-based registration.

Adjacent strips have a certain amount of overlap. A study of the height variations in the common region of two overlapping strips has been made. One strip was measured parallel to the dyke (red dots in Fig. 11), the other one perpendicular to it (blue dots in Fig. 11). Figure 11 depicts the local height of two cross sections in an overlapping zone. Table 1 contains the height differences between the two cross sections of the strips and this for five different samples. For example sample 1 contains the first $1 / 5$ elements of each cross section. As the local height variations are everywhere approx. $9 \mathrm{~mm}$, no systematic errors are present. In other words, the transversal strip lies approximately $1 \mathrm{~cm}$ above the longitudinal one. Although for different strips only an accuracy of $1 \mathrm{~cm}$ is attained relatively to each other, the accuracy in each separate layer is a factor 10 higher.

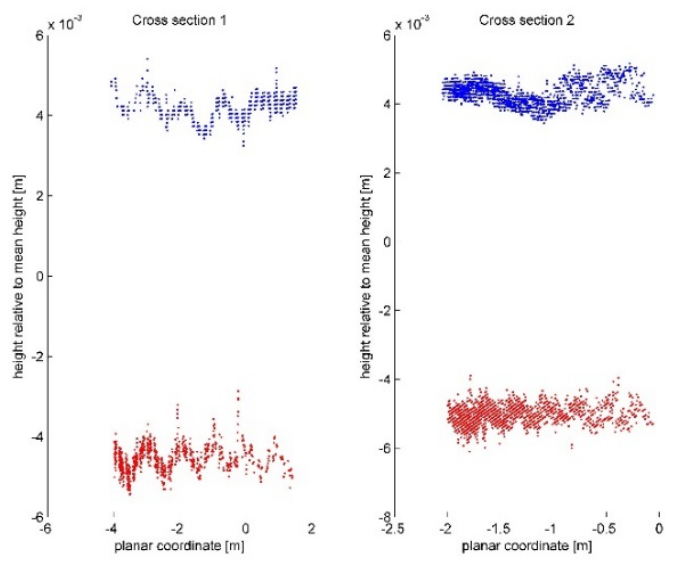

Figure 11: Height difference between longitudinal and transversal MTLS scan of the same region

Table 1: Vertical differences $(\mathrm{mm})$ between longitudinal and transversal strips covering a common region

\begin{tabular}{c|c|c|c|c|c} 
& $\begin{array}{c}\text { Sample } \\
1\end{array}$ & $\begin{array}{c}\text { Sample } \\
2\end{array}$ & $\begin{array}{c}\text { Sample } \\
3\end{array}$ & $\begin{array}{c}\text { Sample } \\
4\end{array}$ & $\begin{array}{c}\text { Sample } \\
5\end{array}$ \\
\hline $\begin{array}{c}\text { Cross } \\
\text { section } \\
1\end{array}$ & 9.0 & 9.1 & 8.8 & 8.4 & 8.6 \\
$\begin{array}{c}\text { Cross } \\
\text { section } \\
2\end{array}$ & 9.4 & 8.9 & 9.3 & 9.5 & 9.5 \\
& & & & &
\end{tabular}

Next to the influence of the system calibration, the quality of the MTLS-based point clouds is heavily depending on the measured distance, the incidence angle and the speed of the platform. Therefore, the speed was limited to $6 \mathrm{~km} / \mathrm{h}$ and the cross section measurement frequency was $20 \mathrm{~Hz}$, resulting in a longitudinal point spacing of approx. $8 \mathrm{~cm}$. The scanner was set to a lateral point spacing of $1 \mathrm{mrad}$, resulting in a distance of $0.5 \mathrm{~cm}$ near the scanning line, to $4.5 \mathrm{~cm}$ at the limits. Erroneous points were manually removed from the data and an Inverse Distance Weight (IDW) interpolation was performed for the calculation of an equidistant grid.

As visible in Figure 12, the point density decreases away from the scan lines. Moreover, a non-linear relation between the measured distance and the point reflection strength appears. This property is used for the adjustment of the intensity values, which represent the received backscatter of the emitted signal. 


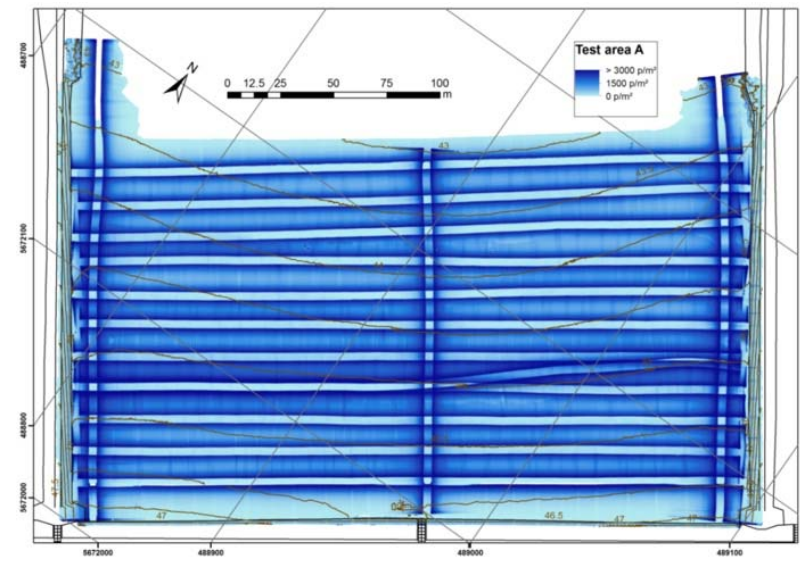

Figure 12: Point density in test area A calculated from the MTLS data (points/m2)

An empirical experiment on the determination of the relation between the intensity value on the one hand and the measured distance, incidence angle and surface properties on the other hand was presented by Voegtle et al. (2009). Under assumption of extended targets with Lambertian reflection, ignorance of the atmospheric transmission factor and a constant power emission, the laser range equation is simplified as (Pfeifer et al. 2007):

$$
I=C \rho \eta_{\text {sys }} \frac{\cos \alpha}{r^{2}}
$$

where

$$
\begin{gathered}
I=\text { intensity } \\
C=\text { constant factor } \\
\rho=\text { surface properties } \\
\alpha=\text { incidence angle } \\
r=\text { measured distance }
\end{gathered}
$$$$
\eta_{\text {sys }}=\text { (non-constant) system transmission factor }
$$

The definition of the incidence angle $\alpha$ and the measured distance $r$ is illustrated in Figure 13.

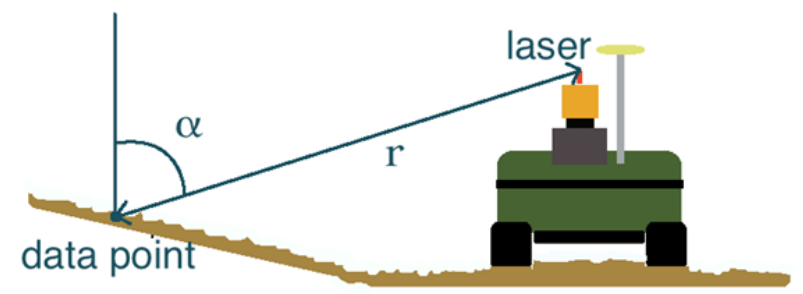

Figure 13: Definition of the distance $r$ and the incidence angle

To show the potential of the MTLS method, the intensity based filter has been applied on a survey line in zone $A$ (Fig. 14). The combination of the Digital Surface Model (DSM) with the reflection strength model provides an improved topography of the area. Intensity variations unveil a change in the surface properties based on which archaeological features or structures can be discovered (Fig. 15) that are not directly observed at the site. In the case of Figure 14, where the intensity values were adjusted using formula (1), the location of a former gully can be observed. It is expected that smaller objects, such as amphorae and flint stones, could be detected with the MTLS method. Further measurements will give a decisive answer.

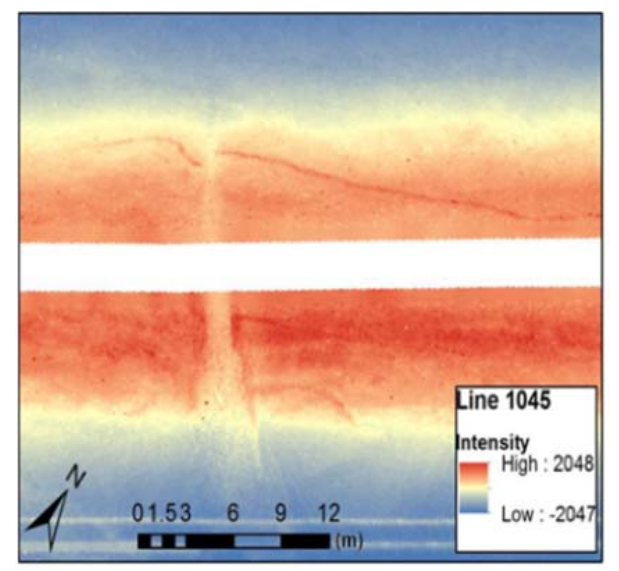

Figure 14: Intensity map acquired from a track line in test area A

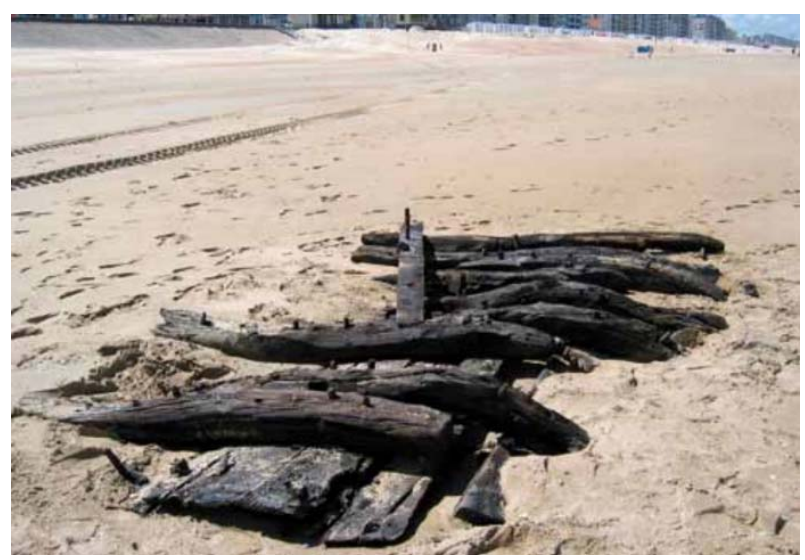

Figure 15: Remains of a wooden shipwreck washed ashore at Sint-Idesbald, Belgium (Pieters et al. 2010).

\section{Conclusion}

The use of MTLS has shown promising results for the construction of DEMs of beaches. Near the laser, a lateral point spacing of $0.5 \mathrm{~cm}$ has been reached. Together with a longitudinal point spacing of $8 \mathrm{~cm}$, this results in very dense point clouds. The suggested work flow of detecting archaeological finds in an efficient manner is as follows: first, ALS can be used to scan larger regions, such that archaeologically interesting zones can be distinguished. Next, MTLS with a horizontal accuracy of a few $\mathrm{cm}$ and vertical accuracy on the millimetre scale is performed. Finally, at zones where micro-ripples indicate a sub-soil object is possibly present, another MTLS measurement can be performed, but with a scanning direction perpendicular to the first MTLS measurement. This will drastically increase the local point density.

Besides attaining high point densities, the used configuration reduces considerably the surveying time; a beach strip of about $150 \mathrm{~m}$ by $300 \mathrm{~m}$ was measured in 45 minutes. The combination of GNSS, INS and a laser scanner definitely improved the accuracy for measuring heights, which is primordial for the measurement of the micro-relief of intertidal areas. Next to the use of this system for DEM reconstruction, the usefulness of the 
measured intensity values has been assessed. In this contribution, a methodology was presented to eliminate the influence of the measured distance and the incidence angle on the intensity values. Indeed, the new intensity values, seen in Figure 14, are independent from the distance and incidence angle after correction. Aberrations in these values are most likely to be caused by differences in sand structure, humidity, or by other features in the sand. Consequently, the proposed procedures can be used as an object recognition technique, allowing micro-morphological feature extraction.

To create an interactive webGIS platform, a good structured spatial database is needed. The presented innovative way for structuring a database offers the advantage of linking archaeological, geophysical and geologic data, solely based on specific characteristics, such as material, location and preservation condition. In this way, no rigid structure has to be followed by archaeological organizations for the huge variety of archaeological objects.

\section{Acknowledgements}

Because the mapping of a cultural heritage is a huge amount of work where a knowledge of different disciplines is required, the SeArch project consists of several specialized research groups. Many thanks go to the project partners of SeArch, who make it possible that our cultural heritage will not be lost forever: Flanders Marine Institute (VLIZ), Flemish Heritage Agency (FHA), Deltares (Department of Geology and Geophysics) and Ghent University (Renard Centre of Marine Geology, Maritime Institute). Special thanks to Prof. Dr. N. Seube and his research team of ENSTA Bretagne for the development of a very reliable, accurate and innovative way for doing mobile terrestrial laser scanning surveys. The authors also wish to thank Clement Aubry and Pierre Simon for their practical assistance during the measurement campaigns and to the Flemish Positioning Service for offering the technology for delivering precise point positions.

\section{References}

ERVYNCK, A., BAETEMAN, C., DEMIDDELE, H., HOLlEVOET, Y., PIETERS, M., SCHELVIS, J., TYS, D., VAN STRYDONCK, M. and VERHAEGHE, F., 1999. Human occupation because of a regression, or the cause of a transgression. A critical review of the interaction between geological events and human occupation in the Belgian coastal plain during the first millennium AD. Probleme der Küstenforschung im südlichen Nordseegebiet, 26, pp. 97121.

HESSE, R., 2010. LIDAR-derived Local Relief Models - a new tool for archaeological prospection. Archaeological Prospection, 17, pp. 67-72. DOI: 10.1002/arp.374

INCOUL, A., NUTTENS, T., DE MAEYER, P., SEUBE, N., STAL, C., TOUZÉ, T. and DE WULF, A. 2014. Mobile laser scanning of intertidal zones of beaches using an amphibious vehicle. 6th International conference on Engineering Surveying (INGEO 2014), Bratislava, Slovakia: Slovenská Technická Univerzita v Bratislave. Stavebná Fakulta. pp. 87-92.

MIDDLETON, J.H., COOKE, C.G., KEARNEY, E.T., MUMFORD, P.J., MOLE, M.A., NIPPARD, G.J., RIZOS, C., SPLINTER, K.D. and TURNER, I.L., 2013. Resolution and accuracy of an airborne scanning laser system for beach surveys. Journal of Atmospheric and Oceanic Technology, 30, pp. 2452-2464. DOI: 10.1175/jtech-d-12-00174.1

MOHAMMADI, H., RAJABIFARD, A. and WILLAMSON, I.P., 2008. Spatial data integrability and interoperability in the context of SDI. In: L. Bernard, A. Friis-Christensen and H. Pundt, eds, Lecture Notes in Geoinformation and Cartography. The European Information Society, pp. 401-413. DOI: 10.1007/978-3-540-78946-8_21.

PFEIFER, N., DORNINGER, P., HARING, A. and FAN, H., 2007. Investigating terrestrial laser scanning intensity data: Quality and functional relations. 8th Conference on Optical 3D Measurement Techniques, 9-12 July 2007, ETH Zurich, Switzerland, pp. 328-337.

PIETERS, M., DEMERRE, I., LENAERTS, T., ZEEBROEK, I., DE BIE, M., DE ClERCQ, W., DICKINSON, B. and MONSIEUR, P., 2010. De Noordzee: een waardevol archief onder water. Meer dan 100 jaar onderzoek van strandvondsten en vondsten uit zee in België: een overzicht. Relicta, 6, pp. 177-218.

SEUBE, N., PICARD, A., TOUZÉ, T., NISTAD, J.G. and RONDEAU, M., 2012. Calibration of vessel mounted LiDAR. Paper presented at the Hydrographic Society Benelux conference Hydro12 - Taking care of the sea, 13-15 November 2012, Rotterdam, The Netherlands.

SKALOUD, J. and LICHTI, D., 2006. Rigorous approach to bore-sight self-calibration in airborne laser scanning. ISPRS Journal of Photogrammetry and Remote Sensing, 61(1), pp. 47-59. DOI:10.1016/j.isprsjprs.2006.07.003.

SNOW, D. R., GAHEGAN, M., GILES, C. L., HIRTH, K. G., MILNER, G. R., MITRA, P. and WANG, J. Z., 2006. Cybertools and archaeology. SCIENCE, 311(5763), pp. 958-959. DOI: 10.1126/science.1121556.

UNESCO, 2001. Text of the 2001 Convention - Convention on the Protection of the Underwater Cultural Heritage. Available: http://www.unesco.org/new/en/culture/themes/underwater-cultural-heritage/2001-convention/ [03/01, 2016]

VOEGTLE, T. and WAKALUK, S., 2009. Effect on the measurement of the terrestrial laser scanner HDS 6000 (Leica) caused by different object materials. International Archives of Photogrammetry and Remote Sensing, 38(3), pp. 6874. 